\title{
Application of CVP-Analysis at the Water Transport Organizations
}

\author{
${ }^{1}$ D.V. Neizvestnaya, ${ }^{2}$ N.N. Kozlova, ${ }^{3}$ N.A. Prodanova \\ ${ }^{1,2}$ Kazan Federal University, Kazan, 420008, Russia \\ ${ }^{3}$ Plekhanov Russian University of Economics, Moscow, 117997, Russia \\ *Email: kozlovakzn@mail.ru
}

\section{Received: 15th December 2017, Accepted: 20th December 2017, Published: 31st December 2017}

\begin{abstract}
The article discusses the possibility and field of application the marginal analysis at the water transport organizations as one of the most advanced management tools. The authors present the currently existing methods of dividing the costs on fixed and variable parts. Considerable attention is paid to the correlation and regression cost analysis. On the basis of such analysis the water cargo transportation organizations' costs division are carried out on to the variable and constant part. Also the regression equations for the different types of costs are made. With such a division the river transport organizations can be more accurately rank the individual business segments in to profitability, identify priority activities that is relevant to the river companies in risky and volatile business conditions.
\end{abstract}

Keywords: Marginal Analysis, Marginal Profit, Variable Costs, Fixed Costs, River Transport.

\section{Introduction}

The stability of the enterprises is conditioned by the maximum profit opportunities for various activities in the changing demand for services, products and market conditions.

Marginal analysis or CVP-analysis is one of the most promising tools for making management decisions in favor of maximizing profit. The methodology of this analysis is based, first, on the correlation between the three major economic indicators - cost, production volume (sales), profit - and secondly, on the prediction value of each of these parameters for a known value of others [1].

The following purposes of marginal analysis are used for exploitation water transport companies [2]:

- Determination of the volume of activity in various areas (transport and extraction of non-metallic construction materials (NCM)) to break even activity,

- Determination of the volume of activity in various areas (transport and extraction NCM) for the given parameters of profit,

- Determination of expected profit on activities and on the whole company for the given volume of cargo transportation,

- Determination of the income dynamics resulting from changes in the value of variable and fixed costs, volume and price on river transportation,

- Determination of priority activities of the shipping companies in the changing situations of market and also a redistribution of vessels on the line of activity; - Evaluation of the efficiency of certain products, services production and enterprise's individual segments;

- substantiation of the optimal solutions regarding to changes in production capacities, purchase of components, the method of the repair works and others in order to minimize costs and maximize profits.

Currently CVP-analysis is one of the most promising areas for forecasting enterprises' activities of inland waterway transport. The use of CVP-analysis can provide a more complete assessment of the activity results of river transport companies' certain segments. Also it can substantiate the choice of management solutions and improve the efficiency of the company's activity [3].

\section{Method}

The essence of the CVP-method is to analyze the ratio between sales (production), cost of sales (production) and profit on the basis of these quantities prediction in the presence of the specified limits. The basis of the marginal analysis is the division of costs relatively production volume on to variable and fixed. Variable costs vary in proportion to the volume of production (services) that is dependent on the level of business activity. Fixed costs remain unchanged relatively to production volumes [4].

However, it should be noted that in a real situation quite rare to find an absolutely constant or variable costs. In most cases, the costs have a semi-variant and semi-permanent character. In addition to various activities of shipping companies the same costs can be of a different character. So, for vessels carriers (passenger and freight) the fuel will be a variable cost, electricity - semi-variable, and for vessels in loading and unloading, on the contrary, electricity appears variable costs, fuel - semi- variable.

The process of dividing the semi-variable and semifixed costs into fixed and variable rather complicated and requires empirical knowledge and the application of mathematical approaches. For dividing costs into fixed and variable in the current practice it is need to use analytical and statistical methods.

The analytical method is represented by the coefficient of reacting costs. The coefficient is the ratio of the changing expenses rate $(\Delta \mathrm{Z} \%)$ and the rate of change in output $(\Delta \mathrm{V} \%)$. 


$$
C_{r c}=\frac{\Delta Z \%}{\Delta V \%}
$$

If the coefficient is zero, i.e. the costs do not react to changes in production, so the cost is constant. If the ratio is equal to one, the costs are variable proportional. If $\mathrm{C}_{\mathrm{rc}}>1$, the variable costs are progressive, that is growing more rapidly than output. If $\mathrm{C}_{\mathrm{rc}}<1$, the costs are digressive variable growing at a slower speed than enterprise's business activity.

Statistical methods for dividing the costs into variables and constants are represented by the following species [5]:

- Graphical method,

- A method of maximum and minimum points,

- Least square method.

The most accurate results can be obtained using the method of least squares, so we choose and scrutinize it in more detail. Also with such method we divide the costs of inland waterway transport organizations in the fixed and variable parts.

Behavior model describes the cost as a linear function of total costs depending on production. In a general form presented model would be:

$$
Y=a+b \cdot x
$$

where $\mathrm{Y}$ - the total amount of a concrete type of costs,

a - the amount of fixed costs,

b - the amount of variable costs per unit of production (services)

$\mathrm{x}$ - volume of production.

The system of normal equations is applicable for estimating the parameters of variable and fixed costs:

$$
\left\{\begin{array}{l}
a \cdot n+b \sum x=\sum y \\
a \sum x+b \sum x^{2}=\sum y \cdot x
\end{array}\right.
$$

where $\mathrm{n}$ - the number of the analyzed periods. On the basis of this number we'll divide costs into fixed and variable.

The amount of variable costs per unit of production (services) - $\mathrm{b}$ - is determined by the formula 1 .

$$
b=\frac{n \sum x y-\sum x \sum y}{n \sum x^{2}-\left(\sum x\right)^{2}}
$$

The amount of the constant part of a certain kind of expenditure is determined by the following formula:

$$
a=\frac{\sum y-b \sum x}{n}
$$

\section{Results and Discussion}

The correlation of variable and fixed costs can vary for the different areas of water transport companies' activity. Besides that, for one activity the bulk of certain costs item, such as electric power may be of variable character (for loading and unloading), and for the transportation this type of costs has a semivariable character. Thus, for a more exact marginal analysis cost-sharing into variable and constant part it is necessary to divide the costs into certain areas of activity [6].

Because of the largest proportion of freight transportation in the shipping companies' activities in the Republic of Tatarstan, we conduct the division of costs into constant and variable parts on the example of cargo transportation. In addition, we consider the formation of model of the marine fuel costs.

Data about transportation volume and fuel costs are shown in Table 1 and Fig. 1 and 2.

Table 1. The Dynamics of Transportation and Fuel Costs

\begin{tabular}{|c|c|c|c|c|c|}
\hline Month & $\begin{array}{c}\text { Transportation } \\
\text { volume, ths. t-km } \\
(\mathbf{x})\end{array}$ & $\begin{array}{c}\text { Fuel costs, ths. } \\
\text { rub. }(\mathbf{y})\end{array}$ & $\mathbf{x}^{\mathbf{2}}$ & $\mathbf{y}^{\mathbf{2}}$ & $\mathbf{x y}$ \\
\hline 4 & 8659 & 1501,1 & 74978281 & 2253301,21 & 12998024,9 \\
\hline 5 & 8882 & 1496 & 78889924 & 2238016 & 13287472 \\
\hline 6 & 8086 & 1484,1 & 65383396 & 2202552,81 & 12000432,6 \\
\hline 7 & 11675 & 1958,4 & 136305625 & 3835330,56 & 22864320 \\
\hline 8 & 9922 & 1541,9 & 98446084 & 2377455,61 & 15298731,8 \\
\hline 9 & 13040 & 2176 & 170041600 & 4734976 & 28375040 \\
\hline 10 & 11273 & 1936,3 & 127080529 & 3749257,69 & 21827909,9 \\
\hline 11 & 8462 & 1494,3 & 71605444 & 2232932,49 & 12644766,6 \\
\hline In total & 71340 & 13588,1 & 747752602 & 21370521,16 & 126298672,9 \\
\hline
\end{tabular}


Fig. 1. The Volume of Cargo Transportation, ths. t-km.

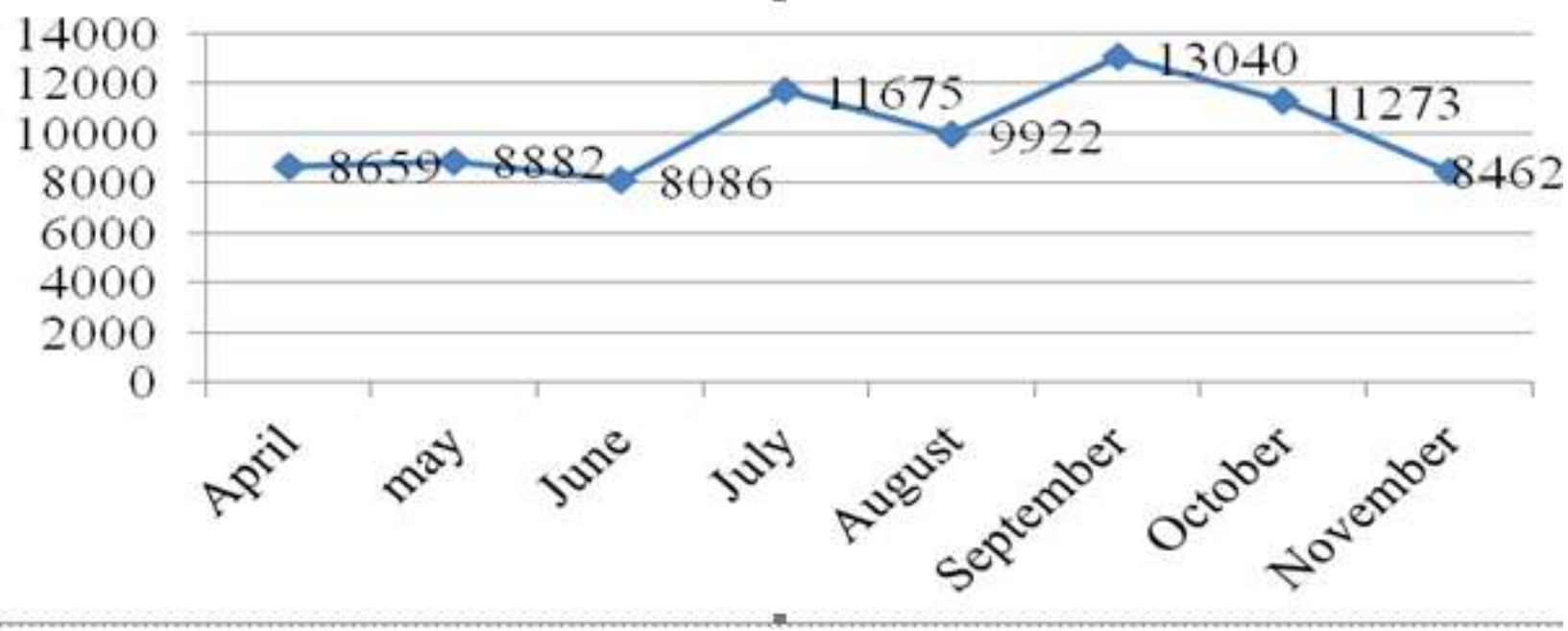

Fig. 2. Fuel Consumption for Transportation, ths. rub

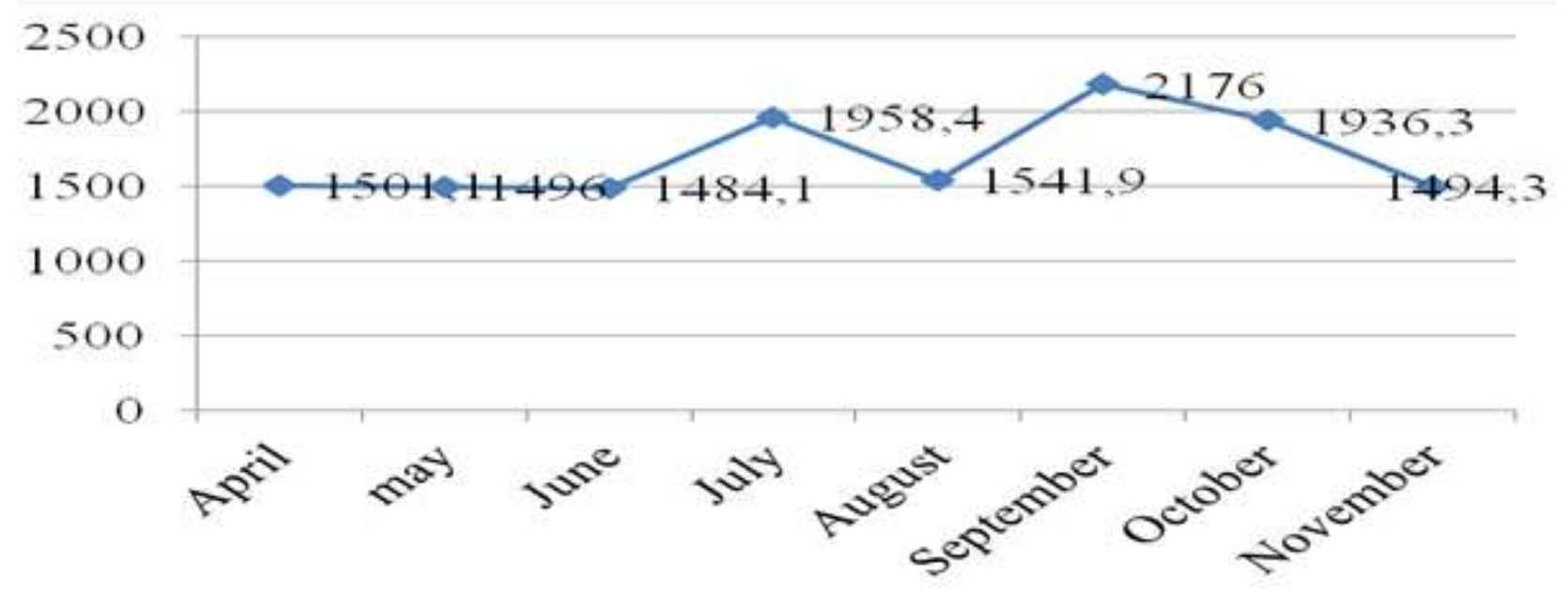

Putting the data under the formula 1, we get the following:

$\frac{8 \cdot 126298673-71340 \cdot 13588}{8 \cdot 747752602-71340^{2}}=0,15$

By putting data under the formula 2 we get:

$$
a=\frac{13588-0,15 \cdot 71340}{8}=360
$$

Thus, the model describing the dependence of fuel costs on freight volumes will be:

$360+0,15 \mathrm{x}$

For determining the correctness of the chosen model and the correlation between the factor and the resulting it is necessary to calculate the index of the linear correlation coefficient (r).

$$
r=\frac{\sum x y-\frac{\sum x \sum y}{n}}{\sqrt{\left(\sum x^{2}-\frac{\left(\sum x\right)^{2}}{n}\right)\left(\sum y^{2}-\frac{\left(\sum y\right)^{2}}{n}\right)}}
$$

The linear correlation coefficient is from -1 to 1 . The closer the coefficient to 1 on the module, the closer link. The sign (-/+) indicates the direction of connection: plus - a direct correlation between the indicators, negative is feedback.

In this example, the correlation coefficient was 0.97 . Since the value of the coefficient is close to 1 , it can be argued that fuel costs are variable costs and are closely related to the volume of traffic.

We test the significance of the regression equation on the F-Fisher criterion. It's necessary to compare the factual $\left(\mathrm{F}_{\text {fakt }}\right)$ and critical (table) $\left(\mathrm{F}_{\text {tabl }}\right)$ value of F-criterion of Fisher. The factual value of the criterion is determined by the following formula: 


$$
F_{\text {fact }}=\frac{\mathrm{r}^{2}}{1-\mathrm{r}^{2}}(n-2),
$$

where $\mathrm{n}-$ the aggregate number of units.

If $\mathrm{F}_{\text {tabl }}$ less than $\mathrm{F}_{\text {fakt }}$, the regression equation is recognized as an important, if $F_{\text {tabl }}$ more than $F_{\text {fakt }}$, the regression equation is unreliable.

According to our data $F_{\text {fakt }}$ will be:
$\mathrm{F}_{\text {fact }}=\frac{0,97^{2}}{1-0,97^{2}} \cdot(n-2)=99,54$

According to the statistical and mathematical tables of Fisher F-criterion at a significance level of 0.05 for $\mathrm{n}=8 \mathrm{~F}_{\text {tabl }}$ be 5.32 .

In our case $F_{\text {fakt }}>F_{\text {tabl }}$ that testifies about the correctness of the chosen regression equation.

Similar calculations using the least squares method on the other types of transportation costs are made.

The results are shown in Table 2.

Table 2. Results of Regression Analysis of Water Transportation's Costs

\begin{tabular}{|c|c|c|}
\hline Types of costs & The regression equation & Correlation coefficient \\
\hline Salaries of employees & $\mathbf{8 2 0}+\mathbf{0 , 0 6} \mathbf{x}$ & $\mathbf{0 , 9 3}$ \\
\hline Free food ration & $\mathbf{5 1 + 0 , 5 x}$ & $\mathbf{0 , 6 7}$ \\
\hline Welfare expenditure & $\mathbf{2 5 6 + 0 , 0 1 7}$ & $\mathbf{0 , 9 7}$ \\
\hline Fuel & $\mathbf{3 6 0 + 0 , 1 5 x}$ & $\mathbf{0 , 9 7}$ \\
\hline Oil & $\mathbf{1 , 0 4 + 0 , 0 0 6 x}$ & $\mathbf{0}$ \\
\hline Payments for complex service of fleet & $\mathbf{0 , 2 5 + 0 , 0 9 x}$ & $\mathbf{0 , 1 5}$ \\
\hline Depreciation & $\mathbf{3 1 7 + 0 x}$ & $\mathbf{0 , 1 7}$ \\
\hline Repair costs & $\mathbf{1 6 1 + 0 , 0 0 7 x}$ & $\mathbf{0 , 8 6}$ \\
\hline Rent cargo and mechanisms & $\mathbf{1 7 8 0 + 0 , 0 0 3 x}$ & $\mathbf{0}$ \\
\hline Disbursements & $\mathbf{6 , 7 + 0 , 0 9 x}$ & $\mathbf{0 , 9 6}$ \\
\hline Insurance costs & $\mathbf{3 8 + 0 x}$ & $\mathbf{0 , 8 7}$ \\
\hline Navigation dues & $\mathbf{1 1 + 0 , 6 x}$ & $\mathbf{0 , 4 8}$ \\
\hline Ship's Communications Services & $\mathbf{7 , 1 + 0 , 0 2 x}$ & $\mathbf{0 , 2 1}$ \\
\hline
\end{tabular}

To evaluate the correlation between the level of business activity and the amount of the costs we use the scale proposed by academician E.P. Golubkov (Table 3).

Table 3. The Ranking of Costs Correlation on a Scale of E.P. Golubkov and Classification of Costs in Relation to the Volume of Cargo Transportation

\begin{tabular}{|c|c|c|c|}
\hline $\begin{array}{c}\text { Correlation } \\
\text { coefficient }\end{array}$ & $\begin{array}{c}\text { Interpretation of } \\
\text { the closeness of } \\
\text { the connection }\end{array}$ & Types of costs & \multirow{2}{*}{ Classification of costs } \\
\cline { 1 - 3 } $\mathbf{0 , 0 0 - 0 , 2 0}$ & Absent & $\begin{array}{c}\text { Depreciation, repair costs, insurance } \\
\text { costs }\end{array}$ & \multirow{2}{*}{ Fixed } \\
\hline $\mathbf{0 , 2 1 - 0 , 4 0}$ & Very weak & Administrative expenses & Semi-fixed \\
\hline $\mathbf{0 , 4 1 - 0 , 6 0}$ & Weak & Other direct costs & Related Variables \\
\hline $\mathbf{0 , 6 1 - 0 , 8 0}$ & Moderate & Welfare expenditure & \multirow{2}{*}{ Strong } \\
\cline { 2 - 2 } & $\begin{array}{c}\text { Wages of seafarers, free food rations, } \\
\text { fuel, oil, payments for complex service } \\
\text { of fleet, disbursements, navigation fees, } \\
\text { the ship's communication services }\end{array}$ & \\
\hline
\end{tabular}


It should be noted that for the marginal analysis it is necessary to exactly divide costs into fixed and variable, so to variable costs will be assigned variables and semi-variable costs from Table 3, to the permanent - permanent and semi-permanent.

\section{Conclusion}

The basis of marginal analysis is a marginal profit the difference between revenue and variable costs (fixed costs plus profit). You can use it for more accurately ranking the individual segments of the company in terms of profitability and also for identifying priority activities. This is relevant for river transport business because its active in a risky and volatile business conditions. Besides that, the marginal profit is the basis for determining the breakeven point for each activity and for the enterprise as a whole. Also it is an effective tool for deciding about the introduction of new activities into the production program [7].

In summary, we can conclude that for the river transport enterprises marginal analysis is substantiated and promising tool for income, expenses and profit managing.

\section{Acknowledgements}

The work is performed according to the Russian Government Program of Competitive Growth of Kazan Federal University.

\section{References}

1. Nesterov, V.N., Akhtyamova, A.S., Domracheva, E.S. Accounting and analysis in managing the cost of innovation // Mediterranean Journal of Social Sciences, Vol 6, No 1 S3 (2015), February 2015 - Special Issue, p.211-217

2. Nesterov, V.N., Neizvestnaya, D.V. Application of optimization models in prediction of inland water transport organizations' profit // Mediterranean Journal of Social Sciences - Vol 5, No 24 (2014): Special Issue - November 2014, p. 154-160

3. Sokolov A.Y., Sungatullina L.B. Management Accounting of Production Overheads by Groups of Equipment / A.Y. Sokolov, L.B. Sungatullina //
Asian Social Science. - 2015. - vol. 11, № 11 may. - P. 379-384

4. A. Y. Sokolov, Y. M. Giniatullin Management Accounting of Costs: Approaches to Calculation of the Target Cost of the Product//Asian Social Science Vol 11, No 11 (2015), Vol. 11, No. 11, May 2015, Special Issue p.95-99

5. Elsukova T.V. Lean accounting and throughput accounting: an integrated approach // MJSS (Mediterranean journal of social sciences)- Vol.6, №3, May 2015, pp.83-87

6. Neizvestnaya D. V., Antonova N. V. Organization of Management Accounting in Water Transportation Companies // Asian Social Science Vol 11, No 11 (2015), May 2015, Special Issue, p. 323-330

7. Sungatullina L.B. Application of Linear Programming in Budgeting Costs for the Compensation of Employees / L.B. Sungatullina // Mediterranean Journal of Social Sciences. - 2014. vol. 5 №25 November. - P. 388-392

8. Needles, B.E., Powers, M., Frigo, M.L., Shigaev, A. Operating characteristics of high performance companies: Strategic direction for management // Studies in Managerial and Financial Accounting v.28, 2014

9. R.R. Azmitov, L.L. Korabelnikova Problems of Implementation of Management Accounting Automation in Russia // Mediterranean Journal of Social Sciences Vol 6, No 1 S3 (2015), February 2015 - Special Issue p.379-384

10. Zhijia Tana, , Wan Lia, Xiaoning Zhangb, Hai Yangc Service charge and capacity selection of an inland river port with location-dependent shipping cost and service congestion // Transportation Research Part E: Logistics and Transportation Review, Volume 76, April 2015, Pages 13-33

11. Strelnik E.U., Usanova D.S., Ushakova T.V. Relationship between Financial Indicators of a Company and the ERP-System Implementation Costs // Mediterranean Journal of Social Sciences Vol 5, No 24 (2014): Special Issue - November 2014 p. $15-20$ 